\title{
PERKEMBANGAN TEORI SASTRA (SUATU PENGANTAR)
}

\author{
Felta Lafamane \\ feltafamane@gmail.cof
}

\begin{abstract}
Abstrak
Secara normatif, studi sastra dibagi dalam beberapa bidang, yakni teori sastra, sejarah sastra, kritik sastra, sastra bandingan dan kajian sastra.Teori sastra mempelajari pandangan orang terhadap sastra. Sejarah sastra berusaha menyusun dan mempelajari karya sastra sebagai bagian dari proses sejarah intelektudal dalam satu masyarakat. Sejarah teori sastra dapat dipandang sebagai bagian dari pemikiran filosofis karena sejarah teori sastra itu sendiri sama halnya dengan sejarah pemikiran umat manusia terhadap objek seni atau sastra yang menekan pada sifat yang lebih praktis pejabaran konsepnya. Teori sastra sendiri pada hakikatnya dapat dipersamakan dengan ilmu keindahan atau estetika. Ilmu dan teori tentu satu hal yang berbeda. Dengan asumsi seperti itu, menulis sejarah teori sastra sama halnya dengan menulis sejarah estetika dalam bidang seni sastra. Namun, sejarah teori perlu diketahui dan dipahami supaya tidak terjadi kesalahan berpikir mengenai kedua hal tersebut. Teori sastra sendiri memiliki berbagai pengertian seiring dengan paradigma yang dibawanya. Teori sastra diartikan sebagai seperangkat ide-ide dan metode yang digunakan untuk praktik pembacaan sastra. Teori sastra juga diartikan sebagai sebuah cara atau langkah memahami sastra. Pandangan dalam teori sastra pun mengalami perubahanperubahan seiring dengan perkembangan cara berpikir manusia.
\end{abstract}

Keyword: perkembangan, teori sastra, sejarah, sastra

Abstract

Normatively, literary studies are divided into several fields, namely literary theory, literary history, literary criticism, comparative literature and literary studies. Literary theory studies people's views of literature.

Literary history seeks to compile and study literary works as part of the process of intellectual history in one society. The history of literary theory can be seen as part of philosophical thinking because the history of literary theory itself is the same as the history of human thought towards art or literary objects which emphasize the more practical nature of the translation of concepts. Literary theory itself can essentially be equated with the science of beauty or aesthetics. Science and theory are certainly one different thing. With such an assumption, writing the history of literary theory is the same as writing aesthetic history in the field of literary arts. However, the history of the theory needs to be known and understood so that there are no mistakes in thinking about these two things. Literary theory itself has various meanings along with the paradigm it carries. Literary theory is defined as a set of ideas and methods used to practice literary reading. Literary theory is also interpreted as a way or step to understand literature. The views in literary theory also experience changes along with the development of human thinking.

Keyword: development, literary theory, history, literature 


\section{Pendahuluan}

Teori sastra dan sejarah sastra dalam kajian ini lebih mendekatkan pada pendekatan sejarah sastra yang tradisional, prinsip dasar sejarah sastra beberapa faktor yang relevan untuk sejarah sastra, penulisan sejarah sastra, dan sejarah sastra Indonesia. Sastra, khususnya sastra Indonesia, sering diidentikan dengan seni dalam tulis menulis oleh masyarakat awam. Hal ini tidak sepenuhnya salah, karena sebuah karya sastra yang dapat banyak aspek yang mendukung sebuah kesenian. Berbicara tentang seni, tidak dapat dilepaskan dari estetika.

Seni memang tidak dapat dipisahkan dari sebuah keindahan walau sebuah seni itu belum tentu indah, namun setiap karya itu sedikit hanya memiliki estetika dimata sebagian orang. Keindahan ada dimanamana. Disetiap pandangan alam terdapat keindahan. Bahkan setiap benda sedikit banyak menyiratkan keindahan, walupun sedikit keindahan dapat ditangkap oleh setiap indera manusia. Dengan indera itulah, manusia menikmati setiap keindahan yang ada. Khususnya karya sastra, manusia dapat merasakan keindahan dari tulisan-tulisan yang mencerminkan pemikiran dari sang penulis.

\section{Sejarah Perkembangan Teori Sastra}

Teori sastra berasal dari kata theria (bahasa Latin). Secara etimologis, teori berarti kontemplasi terhadap kosmos dan realitas. Pada tataran yang lebih luas, dalam hubungannya dengan dunia keilmuan teori berarti perangkat penertian,konsep,proposisi yang mempunyai korelasi,yang telah teruji kebenarannya. Pada umumnya, teori dipertentangkan dengan praktik.setelah setelah suatu ilmu pengetahuan berhasil untuk mengabstraksikan keseluruhan konsepnya pada suatu rumusan ilmiah yang dapat diuji kebenarannya, yaitu teori itu sendiri,maka teori tersebut mesti dioperasikan secara praktis, sehingga cabang-cabang ilmu pengetahuan sejenis dapat dipahami secara lebih rinci dan mendalam.

Teori berfungsi untuk mengubah dan membangun pengetahuan menjadi ilmu pengetahuan. Menurut Fokkema dan Kumme-ibsch (dalam Susiati, S, 2020), penelitian terhadap karya sastra pada umumnya memanfaatkan pada teori-teori yang sudah ada.tradisa seperti ini dianggap memiliki kelemahan sebagai akibat penyederhanaan,eklektisisme,dan penyimpulan yang salah. Keuntungan yang

diperoleh jelas bahwa peneliti diberikan kemudahan,peneliti tinggal menguji kembali dan menyesuaikannya dengan sifat-sifat objek.kecenderungan ini disebabkan oleh beberapa kenyataan sebagai berikut:

1. teori-teori yang sudah ada dengan sendirinya sudan teruji, yaitu melalui kritik sepanjang sejarahnya.

2. teori dianggap sebagai unsure yang sangat penting, lebih dari semata-mata alat

3. belum terciptanya sikap-sikap percaya diri atas hasil-hasil penemuan sendiri, khususnya dalam bidang teori.

Secara genesis dengan demikian dalam proses penelitian teori, diperoleh dua cara, yaitu: 
1. peneliti memanfaatkan teori terdahulu, ada umumnya disebut sebagai teori formal, dengan pertimbangan bahwa teori tersebut secara formal sudah ada sebelumnya.teori formal seolaholah bersifat deduksi dan apriori

2. peneliti memanfaatkan teori yang ditemukannya sendiri.teori yang diperoleh melalui manfaat,hakikat dan abstraksi data yang diteliti,pada umumnya disebut teori substansif sebab diperoleh melalui substansi data.

Kedua jenis reori masing-masing memiliki kelebihan dan kekurangannya. Kekurangannya adalah tidak adannya aktivitas untuk menemukan teori yang baru, sehingga tejadi stagnasi dalam bidang teori.kelemahan teori formal ini terpenuhi oleh usaha peneliti yang mencoba menemukan teori substansif.

Pemanfaatan teori formal menurut Vredenbreght, memiliki kelebihan dalam kaitannya dengan usaha peneliti sepanjang sejarahnya, untuk secara terus-menerus memperbaharui sekaligus mengujinnya melalui data yang berbeda-beda sehingga, teori makin lama makin sempurna. Teori ilmu pengetahuan, khususnya dalam bidang sastra diadopsi melalui pemikiran para sarjana barat. Tradisi seperti ini sering menimbulkan perdebatan diantara para sarjana Indonesia antara yang tidak setuju dengan yang setuju. Kelompk yang pertama menginginkan agar khasanah Indonesia dianalisis dengan menggunakan teori sastra Indonesia, dengan konsekuensi agar sarjana Indonesia dapat menemukan teori-teori sastra yang lahir melalui sastra Indonesia sebagai teori indonesia asli, sebaliknya yang kedua tidak mempermasalahkanperbedaan diantarannya, dengan pertimbangan sebagai berikut:

1. tradisi ilmu pengetahuan berkembang dibarat,demikian pula tradisi sastra

2. karya sastra sekaligus bersifat local dan universal

3. globalisasi, termasuk paradigma postmodernisme menghapuskan perbedaan antara barat dengan timur.

Sebuah teori disebut baik apabila memilii sifat-sifat sebagai berikut:

1. mudah disesuaikan dengan cirri-ciri karya yang akan dianalisis

2. mudah disesuaikan dengan metode dan teori yang menyertainnya

3. dapat dimanfaatkan untuk menganalisis, baik ilmu sejenis maupun berbeda

4. memiliki formula-formula yang sederhana tetapi mengimplikasikan jaringan analisis yang kompleks

5. memiliki prediksi yang dapat menjangkau objek jauh kemasa depan teori dan metode memiliki fungsi untuk membantu menjelaskan dua hubungan gejala atau lebih, sekaligus meramalan modol hubungan yang terjadi.

Teori dan metode disamping mempermudah memahami gejala yang akan diteliti yang lebih penting adalah kemampuannya untuk memotivasi,mengevokasi,sekaligua memodifikasi pikiran peneliti.artinya dengan memanfaatkan teori dan metode tertentu maka dalam pikiran pneliti akan timbul kemampuan untuk memahami gejala sebelumnya yang sama sekali belum tampak. Sebagai alat, teori berfungsi untuk mengarahkan suatu penelitian, sedangkan analisia secara langsung dilakukan melalui instrument yang lebih konkret yaitu melalui metode dan teknik. 
Berbeda dengan objek, aspek kebaruan dalam teori dan metode merupakan syarat pokok.teori yang lama dengan sendirinya harus ditinggalkan, digantikan dengan teori dan metode yang baru.demikian seterusnya sehingga teori yang terakhirlah yang dianggap paling relevan. Intensitas terhadap kebaruan disebabkan oleh hal-hal sebagai berikut:

1. teori dan metode adalah alat dan cara penelitian

2. teori dan metode adalah hasil penemuan

3. teori dan metode adalah ilmu pengetahuan

Karya sastra sebagai objek penelitian, metode dan teori sebagai cara untuk meneliti, berkembang bersama-sama dalam kondisi yang saling melengkapi. Dalam khasanah sastra Indonesia aktivitas penelitian dengan memanfaatkan teori dan metode intuisif ekspresif sudah dimulai sejak periode pujangga baru.pesatnya erkembangan teori sastra selama satu abad sejak awal abad ke-20 hingga awal abad ke-21 dipicu oleh beberapa indikator, sebagai berikut:

1. medium utama sastra adalah bahasa, sedangkan dalam bahasa itu sendiri sudah terkandung problematika yang sangat luas

2. satra memasukkan berbagai dimensi kebudayaan, sedangkan dalam budaya itu sendiri juga sudah terkandung permasalahan yang sangat beragam

3. teori-teori utama dalam sastra sudah berkembang sejak zaman plato dan aristoteles, yang dengan sendirinya telah dimatangkan dengan berbagai disiplin, khususnya filsafat

4. kesulitan dalam memahami gejala sastra memicu para ilmuan untuk mnemukan berbagai cara sebagai teori yang baru

5. ragam sastra sangat banyak dan berkembang secara dinamis, kondisi-kondisi sastra yang juga memerlukan cara pemahaman yang berbeda-beda

\section{Macam-Macam Teori Sastra dan Pengertiannya}

Membicarakan mengenai sastra, pastinya akan membicarakan teori sastra yang menunjang di dalamnya. Sebagai tonggak utamanya berdiri sebuah karya sastra, jelas kehadiran teori sastra menjadi bagian terpenting di dalamnya.

Dalam karya sastra yang menggunakan bahasa Inggris, baik sastra Inggris maupun Amerika masingmasing menganut teori yang sama dalam menjabarkan karya. Berikut akan dibahas tiga teori sastra yang sering digunakan dalam belajar bahasa Inggris melalui karya sastra.

\section{Teori Psikoanalisis}

Teori ini menganggap bahwa karya sastra selalu membahas peristiwa kehidupan manusia. Manusia yang memiliki perilaku yang beragam dipengaruhi oleh kondisi psikologis seseorang yang akan mempengaruhi kehidupannya. Secara langsung karya sastra adalah produk dari jiwa dan pemikiran pengarang yang berada dalam kondisi setengah sadar. Para pakar psikologis yang terkenal dalam pendekatan teori ini adalah Jung, Adler, Freud, dan Brill memberikan banyak kontribusinya terhadap teori ini.. 
Teori ini biasanya terbagi dalam tiga aspek yaitu Id, Ego dan Superego. Id adalah naluri makhluk hidup dalam rangka mempertahankan eksistensinya di muka bumi. Ego adalah komponen kepribadian yang bertanggung jawab dalam menangani sebuah realitas (memuaskan keinginan Id dengan cara yang realitas). Superego adalah pengendali Id dan Ego yang berasal bukan dari diri sendiri melainkan penyerapan standar aturan dan pranata dari pendidikan orang tua dan lingkungan sekitar.

\section{Teori Struktural}

Teori ini tidak memperlakukan karya sastra sebagai objek kajiannya karena yang menjadi kajiannya adalah sistem sastra itu sendiri. Hal ini dapat dilihat dari hubungan berbagai unsur dalam teks sastra sehingga unsur-unsur tersebut berkaitan satu sama lain dalam keseluruhan yang utuh. Teori ini dapat dideskripsikan terpisah dari pengarang ataupun realitas sosial.

\section{Teori Feminisme}

Teori ini adalah cerminan realitas sosial patriarki. Berawal dari gejolak para perempuan yang tertindas oleh sistem sosial patriarki, teori feminisme ini tidak berdiri di dalam satu aliran. Feminisme terdiri atas beberapa aliran seperti aliran liberalis, marxis, sosialis, eksistensialis, psikoanalitik, radikal, postmodern, dll. Tokoh-tokoh terkemuka dalam teori ini adalah Helena Cixous, Virginia Wolf, dan Kate Millet.

Dengan adanya teori ini, semakin banyak bermunculan sastrawati bahkan para wanita yang telah membuat karya sastra dengan menggunakan nama laki-laki mulai berani menunjukan siapa jati diri sebenarnya.

\section{DAFTAR PUSTAKA}

Amanto, B. S., Umanailo, M. C. B., Wulandari, R. S., Taufik, T., \& Susiati, S. (2019). Local Consumption Diversification. Int. J. Sci. Technol. Res, 8(8), 1865-1869.

Amri, M., Tahir, S. Z. A. B., \& Ahmad, S. (2017). The Implementation of Islamic Teaching in Multiculturalism Society: A Case Study at Pesantren Schools in Indonesia. Asian Social Science, 13(6), 125.

Andini, K. NILAI BUDAYA SUKU BAJO SAMPELA DALAM FILM THE MIRROR NEVER LIES KARYA KAMILA ANDINI.

ARYANA, A. PERBANDINGAN GAYA BAHASA DALAM NOVEL ATHEIS KARYA ACHDIAT KARTA MIHARDJA DAN NOVEL TELEGRAM KARYA PUTU WIJAYA: TINJAUAN STILISTIKA.

Azwan, A. (2018). Politeness strategies of refusals to requests by Ambonese community. LINGUA: Jurnal Bahasa, Sastra, Dan Pengajarannya, 15(1), 1-6.

Bin-Tahir, S. Z., Atmowardoyo, H., Dollah, S., Rinantanti, Y., \& Suriaman, A. (2018). MULTILINGUAL AND MONO-MULTILINGUAL STUDENTS'PERFORMANCE IN ENGLISH SPEAKING. Journal of Advanced English Studies, 1(2), 32-38. 
Bin Tahir, S. Z. (2017). Multilingual teaching and learning at Pesantren Schools in Indonesia. Asian EFL Journal, 89, 74-94.

Bin Tahir, S. Z. (2015). The attitude of Santri and Ustadz toward multilingual education at Pesantren. International Journal of Language and Linguistics, 3(4), 210-216.

Bin-Tahir, S. Z., \& Rinantanti, Y. (2016). Multilingual lecturers' competence in english teaching at the university of Iqra Buru, Indonesia. Asian EFL Journal, 5, 79-92.

Bin-Tahir, S. Z., Saidah, U., Mufidah, N., \& Bugis, R. (2018). The impact of translanguaging approach on teaching Arabic reading in a multilingual classroom. ljaz Arabi Journal of Arabic Learning, 1(1).

Bin-Tahir, S. Z., Bugis, R., \& Tasiana, R. (2017). Intercultural Communication of a Multicultural Family in Buru Regency. Lingual: Journal of Language and Culture, 9(2), 8.

Djamudi, N. L., Nurlaela, M., Nazar, A., Nuryadin, C., Musywirah, I., \& Sari, H. (2019, October). Alternative social environment policy through educational values in Kafi'a's customary speech to the kaledupa community of Wakatobi Island, Indonesia. In IOP Conference Series: Earth and Environmental Science (Vol. 343, No. 1, p. 012118). IOP Publishing.

Djunaidi, F. G., Azwan, A. Y. T., Iye, R., \& bin Tahir, S. Z. Decks Range Gola Village Community Begun District Buton District North.

Indonesia, K. K. D. B. Morfologi Bahasa Indonesia.

Iye, R., \& Susiati, S. (2018). NILAI EDUKATIF DALAM NOVEL SEBAIT CINTA DI BAWAH LANGIT KAIRO KARYA MAHMUD JAUHARI ALI (Educative Values in Sebait Cinta di Bawah Langit Kairo by Mahmud Jauhari Ali). Sirok Bastra, 6(2), 185-191.

lye, R. (2018). Tuturan emosi mahasiswa kota baubau dalam ranah demonstrasi.

Iye, R., Susiati, S., \& Karim, K. (2020). Citra Perempuan dalam Iklan Sabun Shinzui. Sang Pencerah: Jurnal Ilmiah Universitas Muhammadiyah Buton, 6(1), 1-7.

Iye, R. (2018). Tuturan dalam Prosesi Lamaran Pernikahan di Tomia Kabupaten Wakatobi. Jurnal Totobuang, 6(2).

Iye, R. H. NILAI-NILAI MORAL DALAM TOKOH UTAMA PADA NOVEL SATIN MERAH KARYA BRAHMANTO ANINDITO DAN RIE YANTI. TELAGA BAHASA,(7), 2, 195-206.

Iye, R. WRITING SKILLS IN SMP USWATUN HASANAH, BURU DISTRICT.

Iye, R. Jl Prof Dr HAR Basalamah No, and Namlea-Kab Buru.". TUTURAN DALAM PROSESI LAMARAN PERNIKAHAN DI TOMIA KABUPATEN WAKATOBI." Kontemporer. Bandung: PT Remaja.

Karim, K., Maknun, T., \& Abbas, A. (2019). Praanggapan Dalam Pamflet Sosialisasi Pelestarian Lingkungan Di Kabupaten Wakatobi. Jurnal IImu Budaya, 7(2), 241-247. 
Mansyur, F. A., \& Suherman, L. A. (2020). The Function of Proverbs as Educational Media: Anthropological Linguistics on Wolio Proverbs. ELS Journal on Interdisciplinary Studies in Humanities, $3(2), 271-286$.

Rahayaan, I., Azwan, A., \& Bugis, R. (2016). The Students' Writing Ability through Cooperative Script Method. Jurnal Retemena, 2(2).

Sadat, A., Nazar, A., Suherman, L. O. A., Alzarliani, W. O. D., \& Birawida, A. B. (2019, October). Environmental care behavior through e-jas model with science edutainment approach. In IOP Conference Series: Earth and Environmental Science (Vol. 343, No. 1, p. 012126). IOP Publishing.

Sadat, A., Sa'ban, L. M. A., Suherman, L. O. A., Bahari, S., Ibrahim, T., \& Zainal, M. (2019, October). Internalization characters of environmental care and disaster response through care partner schools. In IOP Conference Series: Earth and Environmental Science (Vol. 343, No. 1, p. 012125). IOP Publishing.

Salamun, T. (2018). DEIKSIS PERSONA BAHASA INDONESIA DIALEK AMBON [Personal Deixes of Indonesian Leanguage With Ambonese Dialect]. Totobuang, 5, 325-339.

Salamun, T. (2018). RELASI KEKERABATAN BAHASA HITU, WAKAL, MORELA, MAMALA, DAN HILA DI PROVINSI MALUKU [The Family Relationship Language Hitu, Wakal, Morela, Mamala, and Hila in Maluku Province].

Suherman, L. A. (2018). The Analysis of Metaphorical Domain on English "Stab Verb" in Corpora. ELS Journal on Interdisciplinary Studies in Humanities, 1(1), 52-58.

Suherman, L. O. A., Salam, S., Mursanto, D., Efendi, A., Bahar, S. B., \& Kanna, T. (2019, October). The effect of open-air curing on compressive strength of geopolymer mortar containing laterite soil and slaked lime. In IOP Conference Series: Earth and Environmental Science (Vol. 343, No. 1, p. 012133). IOP Publishing.

Susiati, S., \& Iye, R. (2018). Kajian Geografi Bahasa dan Dialek di Sulawesi Tenggara: Analisis Dialektometri. Gramatika: Jurnal IImiah Kebahasaan dan Kesastraan, 6(2), 137-151.

Susiati, S., Iye, R., \& Suherman, L. O. A. (2019). Hot Potatoes Multimedia Applications in Evaluation of Indonesian Learning In SMP Students in Buru District. ELS Journal on Interdisciplinary Studies in Humanities, 2(4), 556-570.

Susiati, S. (2018). Homonim bahasa kepulauan tukang besi dialek kaledupa di kabupaten wakatobi [the homonymon of tukang besi island languange in kaledupa dialect at wakatobi regency]. Totobuang, 6 (1), 109, 123.

Susiati, S. (2020). Emosi Verbal Suku Bajo Sampela.

Susiati, S. (2020). Fenomena Tuturan Emosi Verbal Bahasa Indonesia Suku Bajo Sampela.

Susiati, S. (2020). Nilai Budaya Suku Bajo Sampela Dalam Film The Mirror Never Lies Karya Kamila Andini. 
Susiati, S. (2020). Konsep Pertentangan Dalam Film" Aisyah Biarkan Kami Bersaudara" Karya Herwin Novianto.

Susiati, S. (2020). Strategi AMBT untuk Meningkatkan Kemampuan Membaca Pemahaman Interpretatif Siswa Kelas IV SD Negeri 3 Namlea Kabupaten Buru.

Susiati, S. (2020). Fungsi Konatif Pada Iklan Mesin Cuci Hole-Less Tub Dari Sharp: Analisis Wacana Kritis.

Susiati, S. (2020). GAYA BAHASA SECARA UMUM DAN GAYA BAHASA PEMBUNGKUS PIKIRAN.

Susiati, S. (2020). The Concept Of Togetherness In The Films" Aisyah Biarkan Kami Bersaudara" By Herwin Novianto.

Susiati, S. (2020). Konsep Kebersamaan Dalam Film" Aisyah Biarkan Kami Bersaudara" Karya Herwin Novianto.

Susiati, S. (2020). Teori dan Aliran Linguistik: Tata Bahasa Generatif.

Susiati, S. (2020). Metode Pembelajaran Bahasa Indonesia: Sosiodrama.

Susiati, S. (2020). Rekontruksi Internal Bahasa Bugis dan Bahasa Makassar: Linguistik Komparatif.

Susiati, S. Bahan Ajar: Psikolinguistik.

Susiati, S. (2020). PENTINGNYA MELESTARIKAN BAHASA DAERAH.

Susiati, S. (2020). Morfologi Kelas Kata Dalam Bahasa Indonesia.

Susiati, S. (2020). Semantik: Teori Semantik, Relasi Makna, Marked, Dan Unmarked.

Susiati, Y. T. Risman Iye. A. Kesantunan Imperatif Bahasa Indonesia Suku Bajo Sampela: Balai Pembinaan dan Pengembangan Bahasa. 2018. Kongres Bahasa Indonesia (No. 12, pp. 1-6). Report.

Susiati, S. (2020). Kesantunan Imperatif Bahasa Melayu Ambon.

Susiati, S. (2020). Gaya Bahasa Secara Umum Dan Gaya Bahasa Pembungkus Pikiran: Stilistika.

Susiati, S. (2020). Tuturan Kesantunan Imperatif Bahasa Indonesia Suku Bajo Sampela.

Susiati, S. (2020). Nilai Budaya Suku Bajo Sampela Dalam Film The Mirror Never Lies Karya Kamila Andini.

Susiati, S. (2020). Pengaplikasian Multimedia Hot Potatoes Dalam Evaluasi Pembelajaran Bahasa Indonesia Pada Siswa SMP Negeri 9 Buru.

Susiati, S., \& lye, R. (2018). Kajian Geografi Bahasa dan Dialek di Sulawesi Tenggara: Analisis Dialektometri. Gramatika: Jurnal IImiah Kebahasaan dan Kesastraan. 6 (2), 137-151.

Susiati, S. (2020). Kaidah Fonologi Bahasa Indonesia. 
Susiati, S. (2020). Wujud Morfologi Bahasa Indonesia.

Susiati, S. (2020). Makian Bahasa Wakatobi Dialek Kaledupa.

Susiati, S. (2020). Eksistensi Manusia Dalam Film" Aisyah Biarkan Kami Bersaudara" Karya Herwin Novianto.

Susiati, S. NILAI BUDAYA SUKU BAJO SAMPELA DALAM FILM THE MIRROR NEVER LIES.

Susiati, S. (2020). Konsep Keterasingan Dalam Film" Aisyah Biarkan Kami Bersaudara" Karya Herwin Novianto.

Susiati, S. (2020). Concept Of Conflict In The Films "AISYAH BIARKAN KAMI BERSAUDARA" By Herwin Novianto.

Susiati, S. (2020). Embrio Nasionalisme Dalam Bahasa dan Sastra.

Susiati, S. PERWUJUDAN SIMILE OLEH MERARI SIREGAR DALAM NOVEL AZAB DAN SENGSARA.

Susiati, S. (2020). Nilai Pembentuk Karakter Masyarakat Wakatobi Melalui Kabhanti Wa Leja.

Tahir, S. Z. A. B. (2017). Pengembangan Materi Multibahasa untuk Siswa Pesantren. Unpublish dissertation.

Tahir, S. Z. B. (2015). Multilingual Teaching And Learning At Pesantren. 14 Asian EFL Journal Conference.

Tenriawali, A. Y. (2018). Representasi korban kekerasan dalam teks berita daring tribun timur: analisis wacana kritis [the representation victims of violence in tribun timur online news text: critical discourse analysis]. TOTOBUANG, 6 (1), 1, 15.

Yusdianti, A. (2020). THE REPRESENTATION VICTIMS OF VIOLENCE IN TRIBUN TIMUR ONLINE NEWS TEXT: CRITICAL DISCOURSE ANALYSIS.

Teeuw Andries, Sastra dan IImu Sastra, Jakarta: Pustaka Jaya, 1988 